\title{
As parcerias público-privadas e a infraestrutura no Brasil $^{*}$
}

\section{The public-private partnerships and the infrastructure in Brazil}

\author{
Andre Luiz dos Santos Nakamura**
}

\section{RESUMO}

As parcerias público-privadas foram apresentadas como a solução para a falta de investimento público em infraestrutura no Brasil. Entretanto, tratase de um modelo de contratação complexo que merece todo o planejamento necessário para que se mostre adequado ao interesse público. A opção pelo modelo de parcerias público-privadas nem sempre é a opção mais barata, se comparada ao investimento público. Somente em casos de comprovada maior eficiência do agente privado deverá o Estado optar pelo modelo contratual de parcerias público-privadas, sob pena de grandes prejuízos aos cofres públicos e da consequente responsabilização de agentes estatais.

* Artigo recebido em 26 de julho de 2018 e aprovado em 28 de setembro de 2018. DOI: http:// dx.doi.org/10.12660/rda.v278.2019.80052

** UniversidadePresbiteriana Mackenzie,SãoPaulo,SP,Brasil.E-mail:professorandrenakamura@ gmail.com.

Procurador do Estado de São Paulo. Doutor em direito político e econômico pela Universidade Presbiteriana Mackenzie. Mestre em direito do estado pela Pontifícia Universidade Católica de São Paulo. 


\section{PALAVRAS-CHAVE}

Parcerias público-privadas - infraestrutura - investimento público contratos públicos.

\section{ABSTRACT}

Public-private partnerships were presented as the solution to the lack of fund for investment in infrastructure in Brazil. However, it is a complex contracting model that deserves all the necessary planning to be adequate to the public interest. The option of public-private partnerships is not always a cheaper option compared to public investment. Only in cases of proven greater efficiency of the private agent should the State opt for the contractual model of public-private partnerships, under penalty of great losses to the public coffers and the consequent accountability of state agents.

\section{KEYWORDS}

Public-private partnerships - infrastructure - public investment public contracts

\section{Histórico das parcerias público-privadas}

A Lei no 11.079, de 30 de dezembro de 2004, criou duas novas modalidades de concessões de serviços públicos e obras públicas, além da já prevista na Lei $n^{-}$8.987, de 13 de fevereiro de 1995: a concessão administrativa e a concessão patrocinada. Trata-se da introdução no ordenamento jurídico positivo nacional das chamadas parcerias público-privadas (PPPs).

Não se pode confundir a privatização com a PPP. Em regra, na privatização, o Estado transfere a propriedade de um bem público e a titularidade de um serviço à iniciativa privada. Nas parcerias público-privadas (PPPs) é transferida a execução e gestão do serviço, mas a titularidade do mesmo, bem como a base na qual ele é prestado (o bem público ou a infraestrutura) continuam com o Estado que deverá fiscalizar a atividade do privado. Nesse sentido: 
PPPs não são privatizações. No âmbito das PPP, a responsabilidade pelo fornecimento do serviço público é retida pelo setor público, enquanto que na privatização a responsabilidade passa para o setor privado (o setor público pode manter algum controle regulatório de preços). No âmbito das PPP, não há transferência de propriedade e o setor público continua responsável. [tradução nossa] ${ }^{1}$

A origem das PPPs é a Inglaterra. ${ }^{2}$ Primeiramente, foi criado, em 1992, o programa governamental denominado Private Finance Iniciative (PFI), no governo do primeiro-ministro John Major. ${ }^{3}$ As finalidades da PFI eram: (a) emprego de técnicas de gestão privada em empreendimentos públicos, com a assunção, pelo particular, do controle do projeto a ser implementado; (b) transferência dos riscos econômicos do projeto para o particular que assumiria também o ônus de sua elaboração; e (c) obtenção de maior eficiência na aplicação dos recursos econômicos e financeiros necessários à realização do empreendimento público (o que, na denominação inglesa, resume-se na expressão value for money). ${ }^{4}$

O programa da PFI, no final da década de 1990, sob a administração do trabalhista Tony Blair, sofreu algumas alterações. $O$ particular já não mais seria o único responsável pelo projeto, ou seja, o poder público começou a assumir alguns riscos. Buscou-se trazer responsabilidades do particular e

1 "PPPs are not privatization. Under PPPs, accountability for delivery of the public service is retained by the public sector whereas under a privatization, accountability moves across to the private sector (the public sector might retain some regulatory price control). Under PPPS, there is no transfer of ownership and the public sector remains accountable." United Nations Economic Comission for Europe. Guidebook on promoting good governance in public-private partnerships. p. 4. Disponível em: <www.unece.org/fileadmin/DAM/ceci/publications/ppp.pdf >. Acesso em: 11 fev. 2017.

2 "Trata-se de instituto controvertido, forjado na Inglaterra, ao tempo da sra. Tatcher, e acolhido entusiasticamente pelo Banco Mundial e pelo Fundo Monetário Nacional no cardápio das recomendações aos subdesenvolvidos. A 'parceria público privada', que foi jucundamente auspiciada pelo partido governista - outrora comprometido com os interesses da classe trabalhadora, e hoje ponta-de-lança das aspirações dos banqueiros - , constitui-se na crème de la crème do neoliberalismo, pelo seu apaixonado desvelo na proteção do grande capital e das empresas financeiras. Nem mesmo o Governo do Sr. Fernando Cardoso, em despeito de sua álacre submissão aos ditames do FMI, ousou patrociná-la, talvez por uma questão de decoro." MELLO, Celso Antônio Bandeira de. Curso de direito administrativo. 27. ed. São Paulo: Malheiros, 2010. p. 773, nota de rodapé 77.

3 UNITED KINGDOM. House of Commons. Treasury Committee. Private finance initiative. Seventeenth report of session 2010-12. Disponível em: <https://publications.parliament.uk/pa/ cm201012/cmselect/cmtreasy/1146/1146.pdf>. Acesso em: 13 jan. 2018.

4 CÂMARA, Jacintho Arruda. A experiência brasileira nas concessões de serviços públicos e as parcerias público-privadas. In: SUNDFELD, Carlos Ari. Parcerias público-privadas. 2. ed. São Paulo: Malheiros: 2011. p. 157-179. 
partilhá-las com o poder público. Em razão das mudanças, o programa alterou sua denominação, "saiu a PFI, entrou a PPP, a public-private partnership". ${ }^{5}$

\section{Modalidades contratuais de parcerias público-privadas}

Analisando a experiência internacional, verifica-se a existência de várias formas contratuais de PPPs. As principais são ${ }^{6}$ : i) Buy-Build-Operate (BBO): ${ }^{7}$ transferência do uso de um bem público para uma entidade privada ou pública sob o regime privado, normalmente sob contrato, para que os ativos sejam administrados e operados por um período especificado; ii) BuildOwn-Operate (BOO): ${ }^{8}$ o setor privado financia, constrói, possui e opera uma instalação ou serviço perpetuamente e as restrições públicas são indicadas no acordo original, por meio da autoridade reguladora; iii) Build-Own-OperateTransfer (Boot): ${ }^{9}$ uma entidade privada recebe uma autorização para financiar, projetar, construir e operar uma instalação (e cobrar taxas de usuário) por um período especificado, após o qual a propriedade é transferida de volta para o setor público; iv) Build-Operate-Transfer (BOT): ${ }^{10}$ o setor privado concebe, financia e constrói uma nova instalação regido por um contrato de concessão a longo prazo e opera a instalação durante o período previsto no contrato, ocorrendo a transferência da propriedade ao ente público logo após a conclusão da obra:11 na verdade, tal forma cobre Boot e Blot, sendo a

5 Ibid.

6 Cf. United Nations Economic Comission for Europe. Guidebook on promoting good governance in public-private partnerships. Disponível em: <www.unece.org/fileadmin/DAM/ceci/publications/ ppp.pdf>. Acesso em: 11 fev. 2017.

7 "Buy-Build-Operate (BBO): Transfer of a public asset to a private or quasi-public entity usually under contract that the assets are to be upgraded and operated for a specified period of time. Public control is exercised through the contract at the time of transfer." Ibid, p. 88.

8 "Build-Own-Operate (BOO): The private sector finances, builds, owns and operates a facility or service in perpetuity. The public constraints are stated in the original agreement and through on-going regulatory authority." Ibid.

9 "Build-Own-Operate-Transfer (BOOT): "A private entity receives a franchise to finance, design, build and operate a facility (and to charge user fees) for a specified period, after which ownership is transferred back to the public sector." Ibid.

10 "Build-Operate-Transfer (BOT): The private sector designs, finances and constructs a new facility under a long-term Concession contract, and operates the facility during the term of the Concession after which ownership is transferred back to the public sector if not already transferred upon completion of the facility. In fact, such a form covers BOOT and BLOT with the sole difference being the ownership of the facility." Ibid. Ibid.

11 "A principal diferença entre os projetos BOT e Boot se refere ao momento de transferência ao poder público da propriedade dos ativos vinculados à concessão ("bens reversíveis"). 
única diferença a propriedade da instalação durante a execução do contrato; v) Build-Lease-Operate-Transfer (Blot): ${ }^{12}$ uma entidade privada recebe uma autorização para financiar, projetar, construir e operar um serviço (e cobrar taxas de usuário) durante um período, mediante a contrapartida do pagamento de um valor ao Estado, sob o título de aluguel do bem e do serviço público; vi) Design-Build-Finance-Operate (DBFO): ${ }^{13}$ o setor privado concebe, financia e constrói uma nova instalação sob a forma de um arrendamento de longo prazo, opera a instalação durante esse prazo e transfere a nova instalação para o setor público no final do prazo da locação; vii) Finance Only: ${ }^{14}$ uma entidade privada, geralmente uma empresa de serviços financeiros, financia um projeto diretamente ou usa vários mecanismos, como um arrendamento de longo prazo ou emissão de títulos; viii) Operation \& Maintenance Contract (O\& M): ${ }^{15}$ um operador privado, sob contrato, opera um ativo de propriedade pública por um prazo especificado; a propriedade do bem permanece com a entidade pública; ix) Design-Build (DB): ${ }^{16}$ o setor privado desenha e constrói infraestrutura para atender às especificações de desempenho do setor público, muitas vezes por um preço fixo, de modo que o risco de excesso de custos é transferido para o setor privado; $x$ ) Operation License: ${ }^{17}$ um operador privado recebe uma autorização ou o direito de operar um serviço público, geralmente por um período especificado; isso é frequentemente usado em projetos de TI.

Nos projetos Boot a transferência dos ativos se dá ao término do contrato, enquanto nos projetos BOT a transferência se dá logo após a conclusão da construção". BRASIL. Ministério do Planejamento. Parcerias público-privadas: conceitos básicos. Disponível em: <www. planejamento.gov.br/assuntos/desenvolvimento/parcerias-publico-privadas/referencias/ copy_of_conceitos-basicos>. Acesso em: $1^{\mathrm{o}}$ jan. 2018.

12 "Build-Lease-Operate-Transfer (Blot): A private entity receives a franchise to finance, design, build and operate a leased facility (and to charge user fees) for the lease period, against payment of a rente." United Nations Economic Comission for Europe, Guidebook on promoting good governance in public-private partnerships, op. cit., p. 88.

13 "Design-Build-Finance-Operate (DBFO): The private sector designs, finances and constructs a new facility under a long-term lease, and operates the facility during the term of the lease. The private partner transfers the new facility to the public sector at the end of the lease term." Ibid.

14 "Finance Only: A private entity, usually a financial services company, funds a project directly or uses various mechanisms such as a long-term lease or bond issue." Ibid.

15 "Operation \& Maintenance Contract $(O \& \mathcal{E} M)$ : A private operator, under contract, operates a publicly owned asset for a specified term. Ownership of the asset remains with the public entity. Many do not consider OEM's to be within the spectrum of PPPs and consider such contracts as service contracts." Ibid.

16 "Design-Build (DB): The private sector designs and builds infrastructure to meet public sector performance specifications, often for a fixed price, turnkey basis, so the risk of cost overruns is transferred to the private sector. Many do not consider DB's to be within the spectrum of PPPs and consider such contracts as public works contracts." Ibid..

17 "Operation License: A private operator receives a license or rights to operate a public service, usually for a specified term. This is often used in IT projects." Ibid. 
No direito positivo brasileiro, foram previstas duas modalidades de parcerias público-privadas: as concessões patrocinadas e as concessões administrativas. As concessões patrocinadas foram previstas no art. $2^{\circ} \stackrel{\circ}{\text {, }} 1^{\circ}$, da Lei no 11.079, de 30 de dezembro de 2004. Trata-se de uma concessão de serviço público onde o pagamento do concessionário é feito não somente com as tarifas pagas pelos usuários, mas também pelo poder concedente.

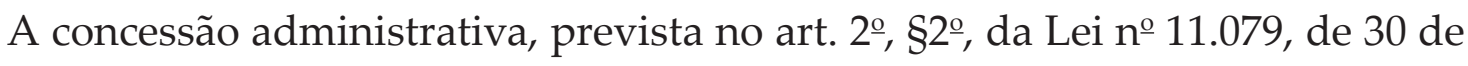
dezembro de 2004, é aquela que poderá ser utilizada em serviços públicos onde não há a cobrança de tarifas, razão pela qual a remuneração do concessionário é paga totalmente pelo poder concedente; não havendo a cobrança de tarifa pelo concessionário, ele é remunerado totalmente pelo Estado, que é o usuário indireto do serviço prestado.

O traço diferencial das PPPs em relação à concessão de serviço público prevista na Lei no 8.987, de 13 de fevereiro de 1995, é a participação do poder público como um pagador direto da remuneração total ou parcial do concessionário. Seria um instrumento para possibilitar a concessão de serviços e obras públicas não rentáveis, ou seja, que não pudessem ser totalmente remunerados pela tarifa paga pelo usuário. ${ }^{18}$

\section{Parcerias público-privadas e infraestrutura}

A PPP foi aclamada como um instrumento imprescindível para fomentar o desenvolvimento da infraestrutura. ${ }^{19}$ Seria uma forma de o Estado, carente

18 Nesse sentido é a lição da Jacintho Arruda Câmara: “As PPPs serão úteis para viabilizar a delegação à iniciativa privada de empreendimentos que, sob o prisma técnico ou econômico, não tenham como se viabilizar mediante remuneração provinda exclusivamente de tarifas cobradas de usuários. São casos em que, pela baixa capacidade contributiva dos usuários ou pela insuficiente demanda prevista para determinado serviço, não se tenha como remunerar o investimento necessário à oferta do serviço como base exclusivamente na receita derivada de tarifas". CÂMARA, Jacintho Arruda. A experiência brasileira nas concessões de serviços públicos e as parcerias público-privadas. In: SUNDFELD, Carlos Ari. Parcerias público-privadas. 2. ed. São Paulo: Malheiros: 2011. p. 157-179.

19 Nesse sentido: "A necessidade de atender à demanda social de infraestruturas e serviços de interesse público não pode ser mantida insatisfeita, pelas Administrações, por um longo período de tempo, embora as restrições orçamentárias não tenham sido completamente resolvidas durante o mesmo, com risco de deterioração irreversivelmente das condições de coesão social e desenvolvimento econômico de um país. Neste contexto, as fórmulas de colaboração públicoprivada podem desempenhar um papel extremamente útil no financiamento e operação de bens e serviços públicos, como demonstrado pela ampla experiência internacional" (tradução nossa). "La necesidad de atender la demanda social de infraestructuras y servicios de interés público no puede mantenerse insatisfecha, por parte de las Administraciones, durante un plazo dilatado de 
de recursos, ${ }^{20}$ mediante a colaboração do setor privado, ${ }^{21}$ realizar obras que não teria condições de realizar sozinho. ${ }^{22}$ Entretanto, não será a PPP, a priori, o instrumento mais eficaz para suprir o déficit de infraestrutura no Brasil. Conforme alerta Marcos Nóbrega, “as PPPs não podem (nem devem), por óbvio, serem tratadas como panaceia ou 'tábua de salvação' para o déficit de investimentos nos diversos países, sobremodo no Brasil". ${ }^{23}$

Deve-se ressaltar que as PPPs podem ser um instrumento extremamente danoso ao interesse público, se mal utilizadas. É prática comum no Brasil os governantes inaugurarem obras e repassarem as contas para seus sucessores. A PPP permite, se utilizada de forma irresponsável, que se inaugurem obras a serem pagas pelas gerações futuras, tendo em vista que a contraprestação do poder público, salvo em relação aos bens reversíveis que podem ser

tiempo, aunque las restricciones presupuestarias no hayan conseguido solventarse plenamente durante el mismo, a riesgo de deteriorar irreversiblemente las condiciones de cohesión social y desarrollo económico de un país. En este contexto, las fórmulas de colaboración público-privada pueden jugar un papel de extremada utilidad en la financiación y operación de bienes y servicios públicos, como demuestra una amplia experiencia internacional". RIDAO MARTíN, Joan. La colaboración entre el sector público y el sector privado en proyectos complejos de infraestructuras y servicios públicos. Una revisión crítica del marco legal en España. Revista Española de Ciencia Política, p. 89-117, mar. 2014.

20 Sobre a possibilidade de se utilizar da PPP para realizar obras em um contexto de restrições orçamentárias: "É nesse contexto de restrição orçamentária e déficit de infraestrutura que surge a Parceria Público-Privada (PPP), um instrumento de política pública capaz de viabilizar projetos que seriam economicamente inviáveis para a iniciativa privada e muito caros para o Estado prover devido a grande restrição orçamentária". MOREIRA, Leandro Capergiani et al. As parcerias público-privadas no Estado de São Paulo: a contribuição ao processo de descentralização da administração pública. Gestão $\mathcal{E}$ Regionalidade, v. 28, p. 33-46, set./dez. 2012)

21 Nesse sentido: “Um programa de parcerias público-privadas, portanto, permite que o setor público ultrapasse barreiras de curto prazo que lhe são impostas - seja pela arrecadação insuficiente de recursos, seja pela limitação, ainda que transitória, da sua capacidade de endividamento -, dividindo a remuneração do investimento realizado pela iniciativa privada em anuais e consecutivas dotações orçamentárias, sempre observadas as diretrizes da Lei de Responsabilidade Fiscal, ressalvadas na Lei das PPPs". DAL POZZO, Augusto Neves; JATENE, Pedro. Os principais atrativos das parcerias público-privadas para o desenvolvimento de infraestrutura pública e a necessidade de planejamento adequado para sua implantação. In: JUSTEN FILHO, Marçal; SCHWIND, Rafael Wallbach (Coord.). Parcerias público-privadas. Reflexões sobre os 10 anos da Lei 11.079/2004. São Paulo: Revista dos Tribunais, 2015. p. 50-71.

22 Nesse sentido: "Muitas vezes, a Administração Pública não tem recursos financeiros ou a capacidade técnica para construir, operar ou manter projetos de infraestrutura ou serviços sociais, muito menos em um ambiente que proíbe o déficit público e proíbe a assunção de despesas a serem custeadas pelo orçamento público a médio ou longo prazo" (tradução nossa). "A menudo, la Administración Pública no tiene los recursos financieros ni la capacidad técnica para construir, operar o mantener proyectos de infraestructura o de servicios sociales, mucho menos en um entorno que proscribe el déficit público y prohíbe la asunción de gastos con cargo a presupuestos públicos a medio o largo plazo." VALLE ZAYAS, Javier. Invertir em infraestructuras em Brasil: las parcerias público privadas. Actualidad Juridica Uriá \& Menéndez, n. 9, p. 81-90, 2004.

23 NOBREGA, Marcos. Direito da Infraestrutura. São Paulo: Quartier Latin, 2011. p. 64. 
adquiridos mediante aporte inicial, ${ }^{24}$ somente pode ser paga após a conclusão da obra. ${ }^{25}$ Não é a PPP um instrumento de diferimento de investimento em infraestrutura, ${ }^{26}$ visto que isso pode ocasionar o comprometimento de vultosas quantias orçamentárias por um período extremamente longo. ${ }^{27}$ Como uma medida de transparência, todas as responsabilidades, riscos e garantias assumidas pelo Estado numa PPP devem ser contabilizados no orçamento público, como forma de se evitar que despesas contratuais sejam assumidas sem recursos financeiros. ${ }^{28}$ Sobre os riscos da contratação de PPPs sem o necessário planejamento, visando à realização de investimentos sem a existência de disponibilidades orçamentárias, segue o alerta de Luis Carranza, Christian Daude e Ángel Melguizo:

Em particular, como a experiência internacional e regional indica, em razão de contratos mal elaborados, regulação imperfeita, instituições deficientes e mudanças macroeconômicas, a implantação pela iniciativa

24 Art. 6º,$\S 2^{\circ}$ da Lei n⿳0 11.079/2044, com a redação dada pela Lei no 12.766/2012.

25 Art. 7º da Lei n⿳0 11.079/2004: "A contraprestação da Administração Pública será obrigatoriamente precedida da disponibilização do serviço objeto do contrato de parceria públicoprivada".

26 Nesse sentido é o alerta de Vitor Rhein Schirato: “O que não poderá ocorrer é uma prática ainda comum no Brasil de utilizar a PPP como forma de diferir os investimentos em infraestrutura. Esta opção, sem dúvidas, implica as escolhas mais caras e menos eficientes, comprometendo a sustentabilidade dos gastos públicos a longo prazo". SCHIRATO, Vitor Rhein. As parcerias público-privadas e políticas públicas de infraestrutura. In: Marçal Justen Filho, Rafael Wallbach Schwind, Parcerias público-privadas, op. cit., p. 73-97.

27 Nesse sentido: "É preciso impedir a banalização da PPP ou o desvio no uso da concessão administrativa, com a utilização do regime jurídico para contratos destinados a se submeterem à Lei 8.666/93, bem como o comprometimento irresponsável de recursos públicos futuros com contratos dessa espécie, seja pela assunção de compromissos impagáveis, seja pela escolha de projetos não prioritários”. GROTTI, Dinorá Adelaide Musetti. A experiência brasileira nas concessões de serviço público. In: Carlos Ari Sundfeld, Parcerias público-privadas, op. cit., p. 180-251.

28 Nesse sentido: “A participação do setor privado em infraestrutura não deve ser usada como um veículo para escapar da disciplina orçamentária, mediante compromissos financeiros dos balanços do setor público. Os projetos de infraestrutura geralmente devem ser refletidos pelos orçamentos do setor público, a menos que todos os riscos relevantes residam verdadeiramente com o setor privado. Além disso, se os riscos são atenuados pelas garantias públicas, colocar esse investimento fora do orçamento torna-se ainda mais questionável" (tradução nossa). "Private sector participation in infrastructure should not be used as a vehicle for escaping budgetary discipline by hiving financial commitments off public sector balance sheets. Infrastructure projects should generally be reflected by public sector budgets unless all relevant risks truly reside with the private sector. Moreover, if risks are mitigated by public guarantees, then placing such investment off budget becomes even more questionable." ORGANISATION FOR ECONOMIC CO-OPERATION AND DEVELOPMENT (OECD). Principles for private sector participation in infrastructure. Disponível em: <www.oecd.org/daf/inv/investment-policy/38309896.pdf>. Acesso em: 2 ago. 2017. 
privada de infraestrutura geralmente resulta em renegociações de contratos e alterações contratauais que geram passivos ao setor público. Portanto, tem-se concluído que as PPPs devem ser a opção somente em setores e atividades onde a gestão e execução pelo parceiro privado possam agregar valor e eficiência que não possam ser disponibilizadas pelo Estado, não devendo ser utilizadas para aumentar o investimento em infraestrutura mediante gastos não existentes no orçamento. ${ }^{29}$ [tradução nossa]

\section{Etapas prévias à contratação de uma parceria público-privada}

A análise acerca da parceria com a iniciativa privada deverá sempre ser norteada pelo critério do interesse público, cabendo a escolha pela PPP somente quando ela se mostrar mais econômica e eficiente que a realização da obra de infraestrutura pelo Estado de forma direta. ${ }^{30}$ Sempre tem que ser realizado o cálculo prévio do value for money ${ }^{31}$ que irá fornecer uma estimativa

29 "In particular, as international and regional experience indicates that, due to a combination of flawed contract design, imperfect regulation, deficient institutions and macroeconomic shocks, private provision of infrastructure often involves renegotiations of contracts and consequent changes in contractual conditions that should be accounted for as contingent liabilities of the public sector. Therefore, the emerging consensus is that PPPS should be pursued in sectors and activities where the private sector management and execution add value and efficiency relative to the public sector, but not to create artificial fiscal space to increase infrastructure investment." CARRANZA, Luis; DAUDE, Christian; MELGUIZO, Ángel. Public infrastructure investiment and fiscal sustainability in Latin America: incompatible goals? OECD Development Centre. Working Paper n. 301, jum. 2011. p.1-40.

30 Nesse sentido: “A escolha entre a utilização da PPP ou do concurso público tradicional deveria ser simples, uma vez que o Estado apenas deveria preferir o primeiro modelo, quando se verificasse uma maior valia, quando comparado com o concurso púbico tradicional". SILVA, José Manuel Braz da. Parcerias público-privadas. Coimbra: Almedina, 2016. p. 91.

31 Sobre o conceito de value for money: "Na sua forma mais simples, o VFM é definido como uma quantificação da redução de custos alcançada pela realização de um projeto de infraestrutura pública através de uma PPP, comparado ao custo de realização da forma tradicional, mediante contratação pública. Os critérios que devem nortear o cálculo do VFM em PPPs são a inovação, a gestão de custos completos do ciclo de vida da obra e a alocação de riscos do projeto decorrentes do contrato, de modo que os governos sejam protegidos em caso de grandes custos e déficits de receita" (tradução nossa). "In its simplest form, VfM is defined as a measure of the extent to which cost savings are achieved when delivering a public infrastructure project through a PPP relative to a traditional government-led procurement approach. Proposed drivers of VfM in PPPs include contracts that encourage innovation, the management of complete lifecycle costs, and the allocation of project risks such that governments are protected in case of large cost overruns and revenue shortfalls." FAROOQI, Naeem; SIEMIATYCKI, Matti. Value for money and risk in public-private partnerships. Journal of the American Planning Association, v. 78, n. 3, p. 268-299, verão 2012. 
dos resultados positivos e das despesas resultantes de uma parceria públicoprivada. $^{32}$

Após, analisa-se o Public Sector Comparator (PSC) - custo da prestação direta dos serviços por meio do próprio Estado ou por meio de entes da administração indireta. ${ }^{33}$ Somente após esse comparativo, poderá ser feita uma opção, técnica e economicamente fundamentada, pela celebração da PPP ou pela realização pelo Estado da obra de infraestrutura e prestação direta dos serviços públicos dela decorrentes. Anoto que o cálculo do PSC é uma tarefa complexa. Ele deve ser decomposto em quatro elementos: risco transferido, neutralidade competitiva, custos básicos e risco retido. ${ }^{34}$

Os riscos representam um critério de extrema relevância para o cálculo do PSC, visando à escolha da forma como deverá ser contratada a obra de infraestrutura. O cálculo do risco deve abranger o risco da execução da obra pelo Estado e o custo da transferência deste risco para o particular. ${ }^{35}$ Todos estes riscos deverão ser valorados e, após, serem separados os riscos transferíveis e os riscos retidos. ${ }^{36}$ Os riscos transferíveis ${ }^{37}$ são aqueles passíveis

32 “Outro aspecto importante é a noção de 'Value for Money' (VFM). Um dos critérios de preferência por este modelo revela-se quando a sua execução conduz a ganhos/benefícios acrescidos, quando comparado com a alternativa de concursos públicos tradicionais. Neste caso diz-se que a PPP conduz a um aumento do 'Value for Money' (VFM)." José Manuel Braz da Silva, Parcerias público-privadas, op. cit., p. 18.

33 "O cálculo do VFM é um dos aspectos cruciais para a tomada de decisão. Existem vários métodos para o seu cálculo, nomeadamente a análise de custo benefício, mas o mais utilizado é o Comparador do Sector Público (CSP). O CSP vai calcular os custos que seriam incorridos pelo sector público, caso este decidisse desenvolver o projeto, de forma independente. O CSP toma por base as melhores práticas de gestão existentes em empreendimentos públicos de dimensões e natureza, semelhantes ao que está a ser avaliado." Ibid., p. 18.

34 "O CSP estima um custo hipotético ajustado ao risco, caso fosse financiado, implementado e gerido pelo Estado. O CSP pode ser decomposto em quatro elementos: Risco transferido, Neutralidade competitiva, Custos básicos, Risco retido. Estes componentes estão identificados, de forma a clarificar o processo de construção deste indicador, que deverá representar o custo total e verdadeiro para a parte pública, relativamente à entrega do output especificado nas condições previstas no concurso público." Ibid, p. 94.

35 "A avaliação do risco no CSP estima o custo total do risco para o Estado, caso a entrega do 'output' se realizasse sob a forma de concurso público. Também representa uma estimativa do valor que o Estado estaria disposto a pagar para transferir este risco, para os concorrentes na opção PPP. Após a identificação e valorização de todos os riscos materiais, estes poderão ser classificados em transferíveis e retidos, dependendo de quais os riscos, que serão afetos aos concorrentes e quais os que serão assumidos pelo Estado, no caso de optar pela PPP, em detrimento do concurso público." Ibid., p. 112.

36 "Após a identificação e valorização dos riscos, cada um deles deverá ser classificado como transferível ou retido, dependendo se será transferido para o proponente ou contido no Estado. O conceito de risco, transferível para o sector privado, subtende que este inicialmente permaneceria no Estado." Ibid., p. 117.

37 "Os riscos transferíveis são todos aqueles que poderão ser transmitidos para o contratado, no âmbito de uma PPP. A decisão de deslocar o risco depende se este está em melhor posição, 
de serem transferidos para o parceiro privado. A possibilidade de transferência não significa que deverão ser transferidos. A decisão acerca da transferência deve considerar os custos da transferência e a possibilidade de melhor

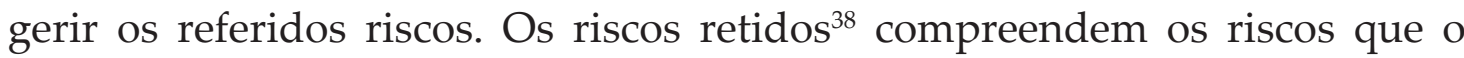
Estado optou por não transferir, bem como aqueles que, por sua natureza, não são passíveis de transferência, como a possibilidade de alterações legislativas que poderão interferir nos custos de implementação e manutenção do projeto de infraestrutura.

Também deve ser computada no cálculo do PSC a denominada neutralidade competitiva. Não se pode nunca esquecer que a infraestrutura se erige num bem de propriedade do Estado o qual tem um tratamento tributário decorrente de imunidades e isenções não extensíveis aos particulares. ${ }^{39}$ Dessa forma, ao se quantificar os custos em que incorreria o privado, deve-se remover os efeitos da propriedade pública e se incluir os custos equivalentes à sua aquisição, ${ }^{40}$ bem como quantificar a tributação que seria atribuída ao privado, para que se possa chegar a um comparativo com o custo do empreendimento de infraestrutura se esta fosse realizada diretamente pelo poder público.

A comparação do custo do PSC com o value for money é essencial antes da decisão governamental de firmar um contrato de parceria público-privada. ${ }^{41}$

para gerir o risco com o menor custo. O tipo e o número de riscos, classificados como transferíveis, necessitam ser avaliados, projeto a projeto e no decurso do tempo, dado que as partes desenvolverão estratégias de gestão e atenuação do risco mais efetivas." Ibid., p. 121.

38 "O risco retido compreende as seguintes parcelas: alterações legislativas; parte do comissionamento ou riscos causados por falhas nas especificações do 'output'; a parcela do risco de procura, que o Estado assume (especificações do "output" contidas no nível base de procura)." Ibid., p. 118.

39 "As vantagens competitivas do setor público incluem sobretudo impostos e diversos tipos de taxas, que estas entidades poderão estar isentas. As desvantagens competitivas poderão ocorrer em consequência da propriedade do sector público e estão relacionadas com o enfoque no escrutínio público e requisitos na apresentação de relatórios detalhados, não obrigatórios no privado." Ibid., p. 108.

40 "A Neutralidade Competitiva elimina as vantagens competitivas, que incrementam o valor do negócio, por o mesmo ser propriedade do Estado. Esta situação permite a avaliação comparativa do 'value for money' entre o CSP e as propostas dos privados, removendo os efeitos da propriedade pública e incluindo custos equivalentes, que de outro modo não seriam incorridos." Ibid., p. 108.

41 "Cumpre lembrar que caso o poder público opte pela modelagem PPP em detrimento das demais modalidades de parceria, deverá provar a superioridade de tal opção. E terá que fazêlo, em primeiro momento, mostrando a vantajosidade econômica da opção, demonstrando os ganhos de escala e atentando para o princípio da eficiência. Além do parâmetro eminentemente econômico, temos que considerar os fatores sociais, como possibilidade de controle social e participação social. Assim, um ponto relevante na opção será uma adequada avaliação do value of money do projeto de PPP." Marcos Nobrega, Direito da infraestrutura, op. cit., p. 61. 
Após a análise do value for money, de acordo com os critérios anteriores, pode-se decidir entre implementar a infraestrutura pública diretamente pelo Estado ou por meio de uma PPP. ${ }^{42}$ Deve-se ressaltar que não existe escolha discricionária, não sendo válida a escolha da PPP somente por questões políticas ou ideológicas ${ }^{43}$ que pregam um ideal de Estado mínimo.

\section{Razões que justificam a contratação de uma parceria público-privada}

\section{A PPP é um contrato que ocasiona altos custos para o Estado. Se o Estado} realiza a obra de infraestrutura e gere o serviço público dele decorrente, em regra, o custo é menor, se comparado a uma PPP, tendo em vista que nesta entra no custo final o lucro do parceiro privado. ${ }^{44}$ Somente se justifica a contratação da infraestrutura por meio de PPPs se resultar ser esta a melhor e menos custosa opção, em razão das características do caso concreto. ${ }^{45}$

42 "A escolha entre serviços públicos e privados de infraestrutura deve ser orientada por uma avaliação objetiva do melhor atendimento ao interesse público, de acordo com o bem comum. Os fatores a serem considerados incluem os níveis atuais de prestação de serviços e a condição de ativos, acessibilidade para famílias e empresas, cobertura de redes, eficiência operacional, manutenção de ativos a longo prazo e sustentabilidade social e ambiental" (tradução nossa). "The choice between public and private provision of infrastructure services should be guided by an objective assessment of what best serves the public interest - that is, supports the common well-being. Factors to be taken into account include the current levels of service delivery and the condition of assets, affordability to households and companies, coverage of networks, operational efficiency, long-term maintenance of assets as well as social and environmental sustainability." Organisation for Economic Co-Operation and Development, Principles for private sector participation in infrastructure, op. cit.

43 "Acresce ainda que a motivação política, econômica ou social para implementar projetos nestes moldes pode prevalecer, negligenciando-se o VFM, o que poderá conduzir a assumir planos de investimentos que se revelarão no futuro dispendiosos, deficitários e injustificados." José Manuel Braz da Silva, Parcerias público-privadas, op. cit., p. 19.

44 "Por decorrência, a infraestrutura quando explorada por parceiros privados exibe uma dupla função: além do interesse público subjacente e remanescente, surge um interesse legítimo privado por parte de quem a explora conjuntamente com a atividade correlata. Isso é devido ao próprio regime de parcerias entre Estado e a iniciativa privada, de forma que, por meio da convergência de interesses, haja o desenvolvimento de uma determinada atividade que atenda à racionalidade publicista e econômica. Por outro lado, quando a infraestrutura é concebida como uma ação do Estado, o interesse público passa a ser o único fator norteador do seu desenvolvimento, sobressaindo-se a racionalidade publicista." CARVALHO, André Castro. Direito da infraestrutura: perspectiva pública. São Paulo: Quartier Latin, 2014. p. 48.

45 "A ênfase nas PPP está nos serviços proporcionados pelo setor privado ao setor público. O Governo paga pelos serviços disponibilizados pelos privados que, no caso das infraestruturas, serão financiados, projetados, construídos, mantidos pela entidade privada. A filosofia na afecção do risco é que a entidade pública liberta-se do risco subjacente ao ativo, nas etapas acima descritas, para se tornar um mero recipiente destes serviços." José Manuel Braz da Silva, Parcerias público-privadas, op. cit., p. 68. 
Se o custo da PPP for maior que o custo da implementação da infraestrutura diretamente pelo Estado, incabível a contratação da PPP.

Somente em casos de comprovado ganho de eficiência ou valor, devidamente comprovado se comparado com a alternativa de implantação e gestão da infraestrutura pelo Estado, é que se pode contratar uma PPP. Quando o Estado opta por uma PPP, em regra, não ocorre qualquer economia de recursos públicos. ${ }^{46}$ Se o projeto é economicamente viável, o Estado abre mão da receita decorrente das tarifas ou preços públicos pagos pelos usuários que poderiam custear total ou parcialmente o projeto de infraestrutura. Se o projeto não for viável, do ponto de vista econômico, ele poderia ser custeado por tributos que custeariam a infraestrutura, sem o acréscimo do lucro do parceiro privado. Assim, o que justificaria uma PPP não seria a economia de recursos (que não existe!), mas a eficiência e a tecnologia não possíveis de serem asseguradas de forma direta pelo Estado. Nesse sentido é a lição de Engel, Fischer e Galetovic:

Nossa conclusão baseia-se na observação de que as PPPs afetam o orçamento público da mesma forma que a contratação pública tradicional. Com uma PPP, o atual governo economiza em gastos de investimento, porém, renuncia à receita de taxas de usuários futuros (se a PPP é financiada com taxas de usuário) ou receitas fiscais futuras (se a PPP é financiada com valores do orçamento público). As exceções são os casos dos governos com restrições de crédito e, mesmo assim, o aumento da disponibilidade de fundos ocorre apenas em condições muito especiais. Por conseguinte, as PPPs devem basear-se em outras razões, principalmente nos ganhos de eficiência associados à construção, manutenção e operações de agrupamento, e não nas suas supostas vantagens financeiras. ${ }^{47}$ [tradução nossa]

46 "É talvez justo dizer que as alegadas vantagens financeiras das PPPs foram um dos principais motivos de sua popularidade. Os artigos de jornal geralmente mencionam que as PPPs liberam fundos do governo, expandindo assim o conjunto de projetos que os governos podem realizar. Em contrapartida, concluímos que não existe uma razão financeira 'prima facie' para preferir PPPs em relação à contratação pública e que as PPP quase nunca liberam fundos públicos" (tradução nossa). "It is perhaps fair to say that the alleged financial advantages of PPPs have been one of the main reasons for their popularity. Newspaper articles often mention that PPPs release government funds, thus expanding the set of projects that governments can undertake. By contrast, we conclude that there is no prima facie financial reason to prefer PPPs over public provision and that PPPs hardly ever free public funds." Engel, Eduardo M. R. A.; Fischer, Ronald D.; Galetovic, Alexander. The economics of infrastructure finance: public-private partnerships versus public provision, EIB Papers, v. 15, n. 1, p. 40-69, 2010. Disponível em: <www.econstor. eu/bitstream/10419/45373/1/657028975.pdf>. Acesso em: 24 jul. 2017.

47 "Our conclusion rests on the observation that PPPs affect the intertemporal government budget in much the same way as public provision. With a PPP, the current government saves in investment 
Nos Estados Unidos da América, até o presente momento, as PPPs não tiveram acolhida. ${ }^{48}$ A razão do desprestígio das PPPs nos Estados Unidos é que o contribuinte americano, bem como o governo, tem a consciência de que toda infraestrutura deve ser custeada mediante recursos orçamentários, seja realizada pelo Estado, seja por meio de PPPs, havendo a preferência pelo investimento do dinheiro público em infraestruturas administradas pelo Estado. ${ }^{49}$ Dessa forma, nos Estados Unidos da América, predomina a implantação e administração da infraestrutura pelo Estado, realizada por meio de investimento público, ${ }^{50}$ por meio dos fundos providos por tributos incidentes sobre combustíveis, bem como pela emissão de títulos públicos destinados ao financiamento da infraestrutura.

outlays. But then it either relinquishes future user fee revenue (if the PPP is financed with user fees) or future tax revenues (if the PPP is financed with payments from the government budget). The exceptions are the case of credit-constrained governments and even then, the increased availability of funds occurs only under very special conditions. Hence, the case for PPPS must rest on something else, notably on efficiency gains associated to bundling construction, maintenance and operations, and not on their purported financial advantages." Ibid.

48 "No entanto, nos Estados Unidos, as parcerias público-privadas representam uma pequena fração das despesas de infraestrutura. Em estradas pedagiadas, por exemplo, onde foram mais utilizadas, representaram apenas 1\% de todas as despesas entre 1989 e 2011, de acordo com um relatório do Ministério do Orçamento do Congresso" (tradução nossa). "Yet in the United States, public-private partnerships represent a tiny fraction of infrastructure spending. On toll roads, for instance, where they have been used the most, they accounted for just 1 percent of all spending between 1989 and 2011, according to a report by the Congressional Budget Office." GOLDSTEIN, Matthew; COHEN, Patricia. Public-private projects where the public pays and pays. The New York Times, 6 jun. 2017. Disponível em: <https://mobile.nytimes.com/2017/06/06/business/ dealbook/trump-infrastructure-plan-privatized-taxpayers.html>. Acesso em: 20 jun. 2017.

49 "Existe um equívoco relevante sobre a forma como as parcerias público-privadas realmente funcionam, disse David Besanko, professor da Escola de Gestão de Kellogg na Northwestern University. 'Os contribuintes ou os usuários precisarão pagar por infraestrutura privada, assim como eles precisam pagar por infraestrutura pública. Você precisará obter receitas de algum lugar" (tradução nossa. "There is a significant misunderstanding of the way public-private partnerships actually work," said David Besanko, a professor at the Kellogg School of Management at Northwestern University. "Taxpayers or users are going to need to pay for private infrastructure just as they need to pay for public infrastructure. You're going to need to get revenues from somewhere." Ibid.

50 "As variações das parcerias público-privadas - conhecidas como acordos P3 em Wall Street são mais comuns no Canadá e em alguns países europeus do que nos Estados Unidos [...] Existe uma razão para isso. A América é uma das poucas nações que isenta os juros sobre os títulos locais e estaduais de impostos federais. Como resultado, o mercado de títulos municipais do país é maior e mais desenvolvido do que na maioria dos outros países, o que torna o financiamento público das infraestruturas muito mais atraente, diminuindo a necessidade de parcerias privadas" (tradução nossa). "Variations of public-private partnerships - known as P3 deals on Wall Street - are more common in Canada and some European countries than in the United States ... There is a reason for that. America is one of the few nations that exempt the interest on local and state bonds from federal taxes. As a result, the nation's municipal bond market is bigger and more developed than in most other countries, and that makes public financing of infrastructure much more attractive, lessening the need for private partnerships." Ibid. 


\section{Conclusões}

Somente deve haver a transferência para a iniciativa privada de um serviço público ou de uma obra de infraestrutura, por meio da PPP, quando essa for a melhor escolha entre as possíveis, ${ }^{51}$ mediante comprovação técnica, lastreada em estudos, não podendo a escolha ser guiada pelo ideal de Estado mínimo e pelo preconceito infundado de que a atividade realizada pelo Estado é sempre menos eficiente que a realizada pela iniciativa privada.

Não se deve colocar as ideologias acima de questões técnicas; não se pode partir do pressuposto de que tudo deve ser repassado para a iniciativa privada; também não se pode partir do pressuposto de que tudo deve ser realizado de forma direta pelo Estado. Somente o caso concreto poderá definir a melhor solução que atenda ao interesse público. ${ }^{52} \mathrm{~A}$ contratação de uma PPP sem uma análise cuidadosa dos riscos transferíveis, do PSC e do value for money, para que sejam demonstrados e comprovados os ganhos de vantajosidade e eficiência do modelo contratual adotado, se comparada à possibilidade de implantação da infraestrutura de forma direta pelo Estado, pode ocasionar prejuízos aos cofres públicos que devem resultar na punição das autoridades que decidiram de forma equivocada, em razão de ato de improbidade administrativa, na forma prevista no art. 10 da Lei no 8.429 , de 2 de junho de 1992.

51 “Não basta apenas analisar quais são as escolhas estatais cabíveis para assegurar a prestação de um serviço público. É fundamental analisar se o Estado adota a melhor escolha; ou, melhor dizendo, se a escolha estatal adotada é a mais eficiente para o caso concreto." SCHIRATO, Vitor Rhein. Concessões de serviços públicos e investimentos em infraestrutura no Brasil: espetáculo ou realidade. In: SUNDFELD, Carlos Ari; JURKSAITIS, Guilherme Jardim. Contratos públicos e direito administrativo. São Paulo: Malheiros, 2015. p. 142-169.

52 "Para projetos financeiramente autossustentáveis, a modelagem de concessões de serviço público (lei 8.987/95) parece ser a mais adequada, pois o empresário, conforme veremos, assumirá os riscos do empreendimento e, decerto, somente o fará sob os auspícios de autossustentabilidade do projeto. No caso de projetos que, sobremodo pelos valores envolvidos e pelos riscos implícitos, que não atraem por completo a iniciativa privada se inserem adequadamente as Parcerias Público-Privadas. Por fim, para projetos que devem ser assumidos integralmente pelo poder público, a tradicional modelagem da lei de licitações (lei 8.666/93) parece ser a mais adequada." Marcos Nobrega, Direito da Infraestrutura, op. cit., p. 61. 


\section{Referências}

CARRANZA, Luis; DAUDE, Christian; MELGUIZO, Ángel. Public infrastructure investiment and fiscal sustainability in Latin America: incompatible goals? OECD Development Centre. Working Paper n 301. jun. 2011. p. 1-40.

CARVALHO, André Castro. Direito da Infraestrutura: perspectiva pública. São Paulo: Quartier Latin, 2014.

DAL POZZO, Augusto Neves; JATENE, Pedro. Os principais atrativos das parcerias público-privadas para o desenvolvimento de infraestrutura pública e a necessidade de planejamento adequado para sua implantação. In: JUSTEN FILHO, Marçal; SCHWIND, Rafael Wallbach (Coord.). Parcerias público-privadas. Reflexões sobre os 10 anos da Lei 11.079/2004. São Paulo: Revista dos Tribunais, 2015. p. 50-71.

ENGEL, EduardoM.R.A.;FISCHER, RonaldD.; GALETOVIC,Alexander. The economics of infrastructure finance: public-private partnerships versus public provision, EIB Papers, v. 15, n. 1, p. 40-69, 2010. Disponível em: <www. econstor.eu/bitstream/10419/45373/1/657028975.pdf>. Acesso em: 24 jul. 2017.

FAROOQI, Naeem; SIEMIATYCKI, Matti. Value for money and risk in publicprivate partnerships. Journal of the American Planning Association, v. 78, n. 3, p. 286-299, verão 2012.

GOLDSTEIN, Matthew; COHEN, Patricia. Public-private projects where the public pays and pays. The New York Times, 6 jun. 2017. Disponível em: <https:// mobile.nytimes.com/2017/06/06/business/dealbook/trump-infrastructureplan-privatized-taxpayers.html>. Acesso em: 20 jun. 2017.

GROTTI, Dinorá Adelaide Musetti. A experiência brasileira nas concessões de serviço público. In: SUNDFELD, Carlos Ari (Coord.). Parcerias públicoprivadas. 2. ed. São Paulo: Malheiros, 2011. p. 180-251.

MELLO, Celso Antônio Bandeira de. Curso de direito administrativo. 27. ed. São Paulo: Malheiros, 2010.

MOREIRA, Leandro Capergiani et al. As parcerias público-privadas no estado de São Paulo: a contribuição ao processo de descentralização da administração pública. Gestão E Regionalidade, v. 28. p. 33-46, set./dez. 2012. 
NOBREGA, Marcos. Direito da infraestrutura. São Paulo: Quartier Latin, 2011.

RIDAO MARTÍN, Joan. La colaboración entre el sector público y el sector privado en proyectos complejos de infraestructuras y servicios públicos. Una revisión crítica del marco legal en España. Revista Española de Ciencia Política, n. 34, p. 89-117, mar. 2014.

SCHIRATO, Vitor Rhein. As parcerias público-privadas e políticas públicas de infraestrutura. In: JUSTEN FILHO, Marçal; SCHWIND, Rafael Wallbach (Coord.). Parcerias público-privadas. Reflexões sobre os 10 anos da Lei 11.079/2004. São Paulo: Revista dos Tribunais, 2015. p. 73-97.

. Concessões de serviços públicos e investimentos em infraestrutura no Brasil: espetáculo ou realidade. In: SUNDFELD, Carlos Ari; JURKSAITIS, Guilherme Jardim (Coord.). Contratos públicos e direito administrativo. São Paulo: Malheiros, 2015. p. 142-169.

SILVA, José Manuel Braz da. Parcerias Público-Privadas. Coimbra: Almedina, 2016.

UNITED KINGDOM. House of Commons. Treasury Committee. Private finance initiative. Seventeenth report of session 2010-12. Disponível em: <https:// publications.parliament.uk/pa/cm201012/cmselect/cmtreasy/1146/1146.pdf>. Acesso em: 13 jan. 2018.

UNITED NATIONS ECONOMIC COMISSION FOR EUROPE. Guidebook on promoting good governance in public-private partnerships. Disponível em: <www.unece.org/fileadmin/DAM/ceci/publications/ppp.pdf>. Acesso em: 11 fev. 2017.

VALLE ZAYAS, Javier. Invertir em infraestructuras em Brasil: las parcerias público privadas. Actualidad Juridica Uriá \& Menéndez, n. 9, p. 81-90, 2004. 